\title{
More Than Just "Stressful"? Testing the Mediating Role of Fatigue on the Relationship Between Job Stress and Occupational Crashes of Long-Haul Truck Drivers
}

\author{
Sergio A Useche $\mathbb{I D}^{1,2}$ \\ Francisco Alonso (iD) ${ }^{1,2}$ \\ Boris Cendales ${ }^{3}$ \\ Javier Llamazares ${ }^{4}$ \\ 'Faculty of Psychology, University of \\ Valencia, Valencia, Spain; ${ }^{2}$ DATS \\ (Development and Advising in Traffic \\ Safety) Research Group, INTRAS \\ (Research Institute on Traffic and Road \\ Safety), University of Valencia, Valencia, \\ Spain; ${ }^{3}$ Faculty of Economic and \\ Administrative Sciences, El Bosque \\ University, Bogotá, Colombia; \\ ${ }^{4}$ Department of Technology, ESIC \\ Business and Marketing School, Madrid, \\ Spain
}

\begin{abstract}
Introduction: Recent evidence consistently highlights the adverse work environment of long-haul professional drivers, whose task structure typically involves the performance of extensive shifts, driving under stressful working conditions. In this regard, job stress and fatigue - that are highly prevalent in this workforce - seem to play a crucial role in explaining this group's negative traffic safety outcomes. The aim of this study was to assess whether work-related fatigue is a mechanism that mediates the relationship between job stress, health indicators and occupational traffic crashes of long-haul truck drivers (LHTD). Methods: The data used in this study were collected from 521 Spanish long-haul truck drivers (97\% males) from all 17 regions of Spain, with a mean age of 47 years.

Results: Utilizing structural equation models (SEM), it was found that work-traffic crashes of long-haul truck drivers could be explained through work-related fatigue that exerts a full mediation between job stress (job strain), health-related factors and traffic crashes suffered during the previous two years.

Discussion: Overall, the findings of this research support that a) stressful working conditions and health issues of drivers have significant effects on traffic crashes, and b) fatigue is a mechanism relating stress-related factors and work-traffic crashes of long-haul drivers. This study highlights the need of stress- and fatigue-management policies and interventions, in order to reduce the crash risk of long-haul truck drivers.
\end{abstract}

Keywords: psychosocial factors at work, long-haul truck drivers, job stress, fatigue, occupational accidents

\section{Introduction}

Although demanding tasks and stressful working conditions have been problematized by occupational researchers in many workforces, comprehensive insights on the mechanisms linking these factors with the wellbeing, health and safety of workers is still a pending challenge for the formulation of occupational policies and strategies aimed at the prevention of job-related risks. ${ }^{1-3}$ During recent decades, several evidence-based interventions on key issues such as stress and fatigue have shown a relative success among workers belonging to various industries, supporting the idea that well-designed preventive and promotive actions, taken by organizations and institutions, may reduce health and safety risks of employees., ${ }^{4,5}$ Nevertheless, in the specific case of transportation workers, who themselves are
Correspondence: Sergio A Useche DATS, Carrer del Serpis 29, 3rd Floor, Valencia, 46022, Spain

Tel +34611317890

Email sergio.useche@uv.es 
considered a "vulnerable" workforce, ${ }^{6}$ occupational "accidents", in addition to having a higher frequency and severity that in most other industries (little remains to be said about traffic crashes and their derived injuries and deaths as a critical public health concern), are enhanced by an extensive set of adverse conditions, eg, highly demanding tasks, time pressure, monotonous trips, varying weather and road conditions, irregular shifts and inadequate resting periods. ${ }^{7}$

Thus, professional drivers do not only frequently report different (physical and mental) health complaints but also display higher levels of job stress and fatigue that might be contributing to their on-road crashes. ${ }^{8,9}$ In previous studies, Hege et al (2019) ${ }^{10}$ and Gómez et al $(2018)^{11}$ have demonstrated how adverse working conditions of professional drivers are linked to adverse outcomes in many different spheres, job performance, health (in both mental and physical contexts) and, of course, occupational safety outcomes. Furthermore, and even though job-related "accidents" are trendy lessening as a consequence of several regulations, policies and improvements in the fields of safety culture and occupational health prevention, workrelated traffic crashes, especially those suffered by longhaul professional drivers, are still conceived as a challenging phenomenon in practically all regions of the world, including Southern and Central Europe, where more effective actions seem to be needed. ${ }^{12,13}$

\section{Stress and Fatigue as Major Contributors to Work-Related Crashes}

The evidence addressing the role of psychosocial and physical working conditions of professional drivers has systematically demonstrated how the typical hazards of their occupational environment are associated with job strain, psychological distress and several physical and mental health disturbances. ${ }^{14}$ Also, and especially in the case of long-haul truck drivers (LHTD), who spend considerably extensive shifts at the wheel on a daily basis, there is frequent mention to work-related fatigue ${ }^{15,16}$ whose prevalence, according to empirical evidence addressing the working conditions of professional drivers, may be enhanced by high rates of job stress. ${ }^{17-20}$

For this study, job stress is approached through the Job Demand-Control model (JDC), ${ }^{21}$ which states that quantitative job demands and worker's decision latitude (or control) influence the workers' health, behavior and performance. The central hypothesis of the model, known as the "job strain hypothesis", claims that working conditions that combine high demands with low control represent work stressors increasing the risk of adverse health and organizational outcomes. This is due to the fact that the concentration of personal resources in stress coping prevents workers from focusing their efforts and skills on both a careful execution of tasks and the compliance of safety-related procedures. ${ }^{22,23}$ Particularly in the field of driving, it is already known that stress is associated with (eg) reduced psychomotor control, poor hazard detection and increased risk-assumption. ${ }^{24,25}$ Likewise, stressrelated factors impair physical and cognitive performance, as well as emotional control, predisposing drivers to counterproductive work behaviors and higher crash rates, as empirically tested by Useche et al $(2018)^{26}$ in a study on public transport drivers.

Previous studies testing the association between job stress, fatigue and safety outcomes of drivers have determined that fatigue may play a crucial role as a statistical mediator between individual variables, job stress and driving safety outcomes of professional drivers. For instance, Useche et al $(2017)^{27}$ found that work-related fatigue fully mediates the relationship between job strain and risky driving behaviors among BRT drivers. Meanwhile, workrelated fatigue, or "need for recovery", is the result of a task-specific effort, which has become troublesome to the point that workers are, either physically or mentally, no longer able to adequately respond to the demands imposed by the task; or, on the other hand, they are able to respond to task-demands only at the cost of an increased effort and task resistance. ${ }^{28}$ In the literature, work-related fatigue has been strongly associated with impaired job performance and negative health outcomes. ${ }^{29,30}$ Specifically, among professional drivers, several empirical studies have related different fatigue measures to poorer driving performance and increased traffic-crash rates. ${ }^{9,31}$

\section{Objective and Hypotheses of the Study}

In view of the aforementioned considerations, the objective of this study was to test whether work-related fatigue is a mechanism that mediates the relationship between job strain, health indicators and occupational traffic crashes of Spanish long-haul truck drivers. In this regard, and based on the evidence provided by the existing literature, it is hypothesized that (H1) job strain is positively associated to fatigue (H2) fatigue is positively related to work-traffic crash rates, and that, globally (H3), fatigue exerts the role of statistical 
mediator in the relationship between job strain and the occupational crashes suffered by long-haul truck drivers.

\section{Methods and Materials}

\section{Sample}

The sample used for this study was collected from 521 professional long-haul (freight) truck operators, from all the 17 Spanish regions (this was a nationwide sample). Regarding driver's sex, and as it was anticipated bearing in mind the overrepresentation of men in the transportation industry, $96.7 \%$ of them were males. The mean age of the sample was $M=47(\mathrm{SD}=8.2)$ years, being 24 years the minimum and 69 the maximum.

The daily driving intensity was $M=7.9(\mathrm{SD}=1.8)$ hours/day, and the mean amount of days driving a week was $M=5.2(\mathrm{SD}=0.6)$ days/week. As for their occupational safety incidents (ie, crashes in the field of professional driving), the average occupational-crash rate of the last two years was $M=0.36(\mathrm{SD}=1.1)$, and the average amount of traffic sanctions during these 2 years was $M=$ $1.42(\mathrm{SD}=2.3)$. Further socio-labor data of the study sample are presented in Table 1.

\section{Study Design and Procedure}

In this cross-sectional study, participants were directly invited to take part in the study by means of the occupational health departments from their companies. Therefore, the sample was recruited by means of a convenience

Table I Socio-Labor Features of the Study Sample

\begin{tabular}{|c|c|c|c|}
\hline Feature & Category & Frequency & Percentage \\
\hline \multirow[t]{2}{*}{ Gender } & Female & 17 & $3.3 \%$ \\
\hline & Male & 504 & $96.7 \%$ \\
\hline \multirow[t]{4}{*}{ Hours driving a day } & $<5$ hours & 53 & $6 \%$ \\
\hline & $5-8$ hours & 280 & $53.8 \%$ \\
\hline & $9-12$ hours & 207 & $39.7 \%$ \\
\hline & $>12$ hours & 3 & $0.5 \%$ \\
\hline \multirow[t]{6}{*}{ Days driving a week } & 3 or less & 4 & $0.8 \%$ \\
\hline & 4 & II & $2.1 \%$ \\
\hline & 5 & 381 & $73.1 \%$ \\
\hline & 6 & 103 & $19.8 \%$ \\
\hline & 7 & 16 & $3.1 \%$ \\
\hline & There's no regularity & 6 & $1.1 \%$ \\
\hline \multirow[t]{2}{*}{ Shift working } & Yes & 219 & $42.5 \%$ \\
\hline & No & 302 & $57.5 \%$ \\
\hline \multirow[t]{2}{*}{ Type of vehicle driven } & Light-mid truck & 42 & $7.5 \%$ \\
\hline & Heavy truck & 479 & $92.5 \%$ \\
\hline
\end{tabular}

sampling method, grounded on the availability of the study population and their willingness to participate in the study. The data collection process lasted around six months. All long-haul truck operators were asked to willingly fill the questionnaire during (approximately) $45 \mathrm{~min}$ utes of their formation sessions, which were facilitated by their organizations. Participants completed a paper-based questionnaire, whose application was always supervised by a member of the research staff, in case they had doubts about its contents or resolution criteria. They were informed of their rights and the protection of their personal data through an informed consent form, individually signed prior to their partaking in the survey. The global response rate was about $70 \%$ of all the drivers invited to participate in the study.

\section{Description of the Questionnaire}

We used a questionnaire composed of various instruments, aimed at assessing stress and fatigue-related factors framed into the occupational field, that had been previously applied to similar collectives of transport workers with satisfactory results and discriminant capacity. The final version of the research form of four parts:

The first part addressed job stress, approached for this study from Karasek's Job Demand-Control model. For this purpose, the 20-item Job Content Questionnaire (JCQ) ${ }^{21}$ (Karasek, 1998) was applied in its Spanish version, which was initially validated by Gómez (2011), ${ }^{32}$ and reevaluated among professional drivers by Useche et al (2017). ${ }^{17}$ This inventory consists of five sub-scales: skill discretion $(\alpha=0.72)$; decision authority $(\alpha=0.75)$; psychological demands $(\alpha=0.85)$; supervisor and manager support $(\alpha=0.86)$; peer support $(\alpha=0.80)$. Control $(\alpha=0.65)$ is understood as the sum of skill discretion and decision authority. The job strain (JS) index is estimated as: JS= (Demands $\times 2$ )/Control. In this regard, JS coefficients $>1$ indicate the presence of job stress.

The second part of the instrument consisted of the Sluiter's Need for Recovery Scale (NFR) ${ }^{33}$ that has been widely applied to professional drivers showing satisfactory results, ${ }^{17}$ and favorable test-retest reliability and sensitivity for assessing fatigue in occupational scenarios. ${ }^{34}$ This 11 -item dichotomous scale is used to measure workrelated fatigue with a reliability of $\alpha=0.79$, which is very similar to the reliability obtained in a number of previous studies, oscillating between $\alpha=0.68$ and $\alpha=0.80 .^{28,34}$ The NFR test is based on the sum of the positive responses to the overall checklist of possible work-related fatigue 
symptoms, ranging between [0-11]. Given that they are designed to be applied in diverse organizational contexts or workforces working under different conditions, both the JCQ and the NFR questionnaires use a temporally unspecific formulation, which refers more to the level of agreement with a series of situations and conditions related to the work ("please indicate to what extent do you agree with the following statement") than to a punctual time frame, as observed (eg) in health and crash-related questionnaires.

In the third part of the questionnaire, two healthrelated variables were assessed: firstly, the general health status was assessed by means of the self-reported General Health Index (GHI), which is a single continuous value ranging between 0 (poor self-reported physical health) to 10 (excellent physical health) used in psychosocial research by instruments such as the Copenhagen Psychosocial Questionnaire (COPSOQ). ${ }^{35}$ As for the second, psychological distress was assessed by means of the abbreviated version of the Goldberg's $(1992)^{36}$ General Health Questionnaire or GHQ, a 12item Likert questionnaire (scale 1-4; possible scores ranging [12-48]) aimed at assessing different symptoms that might potentially affect the mental health of individuals in a single factor $(\alpha=0.74)$. Both of these measures uniformly refer to the assessment of respondent's perceived health-related conditions during the last month.

Finally, the fourth part of the questionnaire inquired some specific questions related to: a) demographic factors, including age, gender, education level and city/region of residence and b) occupational-driving variables, such as current occupation, type of vehicle(s) driven at work (type(s) of truck), daily intensity of driving (hours), days driving a week, shift work (dichotomous question) and road safety outcomes, defined for this study as the number of crashes suffered over the last two years during job trips.

The 2-year period considered for the self-reported number of occupational or work-related crashes was incorporated to this research in view of previous researches dealing with professional drivers using (eg) similar study factors, instruments and theoretical frameworks, same as work traffic crashes as dependent or predicted variable. Methodologically, most of these studies agree on the fact that it constitutes a time window wide enough to collect positive crash cases but not too long to forget or underestimate those that may have been suffered too much before (for a summary, see ${ }^{19,26,37-39}$ ).

\section{Ethics}

The ethical approval for this research was granted by the Research Ethics Committee of the University of Valencia (IRB H1517828884105), certifying its accordance with the Declaration of Helsinki. The involvement of this study was anonymous, implying no potential risks for the integrity of participants. Neither confidential nor sensitive data allowing to identify participants were collected. Furthermore, an Informed Consent Statement including ethical declarations was read and signed by participants before they completed the questionnaire.

\section{Data Processing}

After a careful data curation process, descriptive statistics were calculated, and questionnaire factors were scored. Bivariate (Pearson) correlations were used to examine the measures of association between study variables. Apart from the correlational exploration (that is bivariate), the relationships among job stress, work-related fatigue and the number of traffic crashes suffered along the last two years were assessed through 3D graphical analysis. The statistical mediation of work-related fatigue between job stress (job strain), health-related factors and worktraffic crashes suffered along the last two years were tested, controlled by age and daily shift (driving) intensity, and the correlation between jobs train and psychological distress were tested using path analyses (Structural Equation Modeling - SEM - with maximum likelihood estimations), with differential significance level criteria for $p<0.05, p<0.01$, and $p<0.001$. Structural equation modeling is a multivariate technique that, following a conceptual model, path diagrams and system of linked regression-style equations, allows researchers to establish complex and dynamic relationships within a web of observed and unobserved variables. ${ }^{40}$ Path analyses used in SEM models can be understood as a collection of statistical techniques used to determine the degree to which a proposed theoretical model is supported by the actual data retrieved from an empirical sample. ${ }^{41}$

As suggested in specialized literature, the model fit was weighed by means of several estimators and indexes from different logics and families (for further information, please refer to Marsh et al $2004^{42}$ ). Precisely, the most relevant accessible indexes suggested for the method of estimation were used: $\chi^{2}$ minimum discrepancy ratio (CMIN/df); Confirmatory Fit Index (CFI), Normed Fit Index (NFI), Tucker-Lewis Index (TLI), Incremental Fit 
Index (IFI) and Root Mean Square Error of Approximation (RMSEA), as suggested by Marsh et al (2004). ${ }^{42}$ A brief description of these indexes and their suggested cut-off points are presented in Table 2 .

All statistical analyses were performed using (IBM SPSS (Statistical Package for Social Sciences), version 26.0, and CIBM SPSS AMOS, version 26.0, specifically employed for structural equation-modeling. 3D graphs were performed through Sigma Plot software, version 12.0 .

\section{Results}

The correlational analysis allowed for the establishment of significant and coherent correlations between health factors (GHI for general physical health and GHQ's psychological distress as a mental health index), job strain, fatigue and worktraffic crashes, as shown in Table 2. In brief, GHI (negatively), psychological distress and job strain (positively) scores were associated with the need for recovery (work-related fatigue), and NFR scores were positively correlated to the rate of traffic crashes suffered over the last two years.

The descriptive scores obtained for each of the study variables are also referred in Table 3 to be contrasted with the outcomes of other studies that used similar questionnaires.

Further, the graphical analysis of the relationships between job stress (job strain), work-related fatigue (need for recovery) and the rate of work-traffic crashes suffered along the last two years has shown how higher crash rates are also clustered in higher-stress and higher-fatigue intercepts than subjects having suffered less (or not suffering) crashes, as shown in Figure 1.

\section{Structural Equation Modeling}

Considering the theoretically based assumptions and empirically tested relationships between the study variables, and bearing in mind the study hypothesis, we carried out a SEM analysis for explaining the long-haul

Table 2 Goodness-of-Fit Indexes Used for Assessing the Structural Model

\begin{tabular}{|c|c|c|c|}
\hline Index & Description & Range & Optimal Values \\
\hline RMSEA $^{\mathrm{a}}$ & $\begin{array}{l}\text { RMSEA is a badness-of-fit measure, ie, an absolute fit index allowing to assess how far a hypothesized } \\
\text { model is from a perfect model. }{ }^{66,67}\end{array}$ & $0-1$ & $\begin{array}{l}<0.080 \text { (better if } \\
\quad<0.060)\end{array}$ \\
\hline $\mathrm{CFI}^{\mathrm{b}}$ & $\begin{array}{l}\text { Introduced by Bentler (1990). }{ }^{68} \text { Constitutes a normed fit index comparing the fit of a hypothesized } \\
\text { model with that of a baseline model. }\end{array}$ & $0-1$ & \multirow[t]{4}{*}{$\begin{array}{l}>0.900 \text { (better if } \\
>0.950)\end{array}$} \\
\hline TLI $^{\mathrm{b}}$ & Measures a relative reduction in misfit per degree of freedom. ${ }^{67}$ & $0-1$ & \\
\hline $\mathrm{NFI}^{\mathrm{b}}$ & $\begin{array}{l}\text { The Bentler-Bonett Normed Fit Index assesses model fit through a comparison of the model of } \\
\text { reference to a model of completely uncorrelated variables. }{ }^{69}\end{array}$ & $0-1$ & \\
\hline $\mathrm{IFI}^{\mathrm{b}}$ & $\begin{array}{l}\text { The Incremental Fit Index }\left(\Delta_{2}\right) \text { adjusts the normed fit index to the sample size and degrees of freedom } \\
\text { of the retained model. }{ }^{70}\end{array}$ & $0-1$ & \\
\hline $\begin{array}{l}\text { CMIN/ } \\
\mathrm{df}^{\mathrm{a}}\end{array}$ & It is the ratio between the Chi-square test value and the degrees of freedom used. & None & $<5.0$ \\
\hline
\end{tabular}

Notes: ${ }^{a}$ Lower values are indicative of a better fit; ${ }^{b}$ higher values indicate a better fit.

Table 3 Bivariate Correlations (Pearson) Between Study Factors

\begin{tabular}{|c|c|c|c|c|c|c|c|c|c|}
\hline \multicolumn{2}{|c|}{ Variable } & Mean & SD & 2 & 3 & 4 & 5 & 6 & 7 \\
\hline I & Age & 47.16 & 8.19 & 0.079 & $-0.205^{* *}$ & -0.026 & $-0.088 *$ & -0.030 & $-0.146 * *$ \\
\hline 2 & Daily Shift Intensity (hours) & 7.90 & 1.81 & - & $-0.089 *$ & $0.114 *$ & $0.227^{* *}$ & $0.179 * *$ & 0.019 \\
\hline 3 & General Health Index ${ }^{a}$ & 7.24 & 1.84 & & - & $-0.468^{* *}$ & $-0.235^{* *}$ & $-0.44 I^{* *}$ & -0.075 \\
\hline 4 & Psychological Distress ${ }^{b}$ & 24.68 & 4.71 & & & - & $0.407 * *$ & $0.550 * *$ & $0.178^{* *}$ \\
\hline 5 & Job Strain ${ }^{c}$ & 1.05 & 0.32 & & & & - & $0.433^{* *}$ & $0.135^{* *}$ \\
\hline 6 & Work-related Fatigue (NFR) ${ }^{d}$ & 7.67 & 1.78 & & & & & - & $0.101 *$ \\
\hline 7 & Work Traffic Crashes ( 2 years) & 0.36 & 1.04 & & & & & & - \\
\hline
\end{tabular}

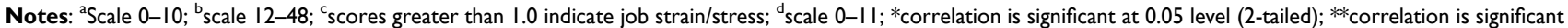
at 0.01 level (2-tailed). 


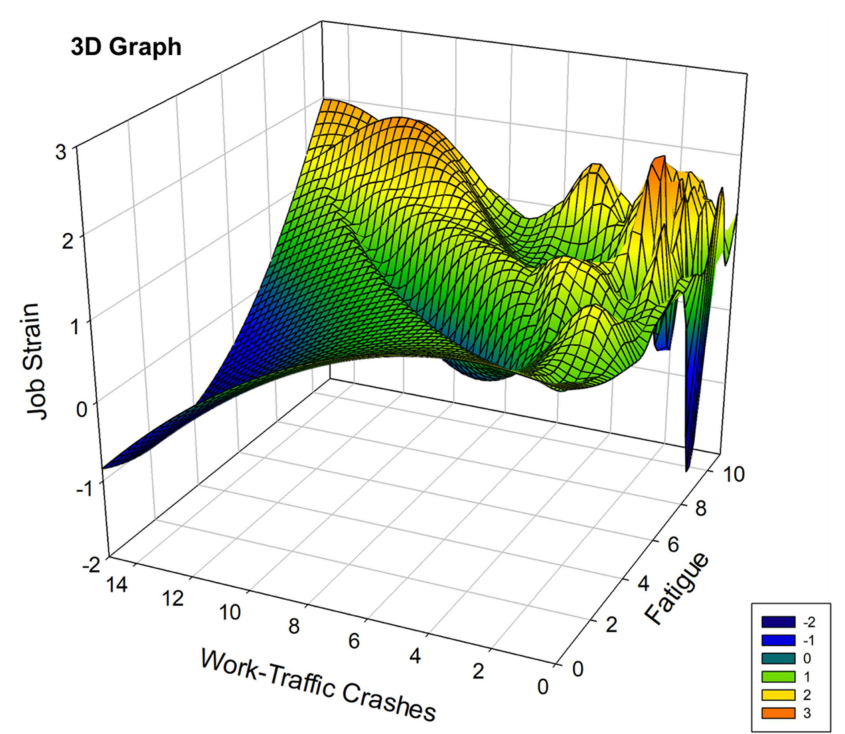

Figure I 3D Graph for assessing the linear relationships among job stress (job strain), fatigue and work-traffic crashes suffered by long-haul truck drivers (LHTD).

freight driver's traffic crash rates suffered along the last two years.

The resulting Structural Equation Model $\left(x^{2}(3)=\right.$ 13.444, $p=0.002 ; \mathrm{NFI}=0.978 ; \mathrm{CFI}=0.986 ; \mathrm{TLI}=0.940$; $\mathrm{IFI}=0.986$; RMSEA $=0.057$, IC90\%: 0.021-,095; CMIN/ $\mathrm{df}=2.689$ ), presented in Table 4 and graphically exposed in Figure 2, shows that work-related fatigue fully mediates the relationship between job strain (JDC model's index of job stress) and the work traffic crashes suffered by longhaul freight drivers.

That is, perceived job strain and driving shift intensity do not directly relate to traffic crash rates, but do so when mediated by work-related fatigue. In the model, the RMSEA was $<0.06, \mathrm{CFI} / \mathrm{NFI} / \mathrm{TLI} / \mathrm{IFI}$ values are optimal $>0.94$, and CMIN/DF was $<5.0$, according to the reference values and cut-off points appended in Table 2. All standardized parameter estimates are presented in Figure 1, in which the unidirectional arrows indicate the direction of the explanatory relationship between the study variables included in the model.

The standardized path coefficients (see Table 3 and values next to solid lines in Figure 2) of the model suggest positive associations between job strain and fatigue, and between fatigue and traffic crashes. Meanwhile, the association between a) general physical health and fatigue was negative, but it was positive when relating psychological distress to fatigue. In other words, the path analysis reveals that high job strain, low physical health and higher rates of psychological distress lead to higher general fatigue, which in turn leads to greater rates of work-traffic crashes.

In other words, and as depicted in Figure 2, six direct effects were significant. General physical health, psychological distress and job strain significantly explained the need for recovery (NFR), while age and daily driving intensity and NFR directly explained WTCs. The latter (apart from the correlations appended in Table 3) is consistent to the two first hypotheses of this study: hypothesis 1 (H1), where job strain has a positive effect on fatigue, and hypothesis 2 (H2), proposing that fatigue could be positively related to work-traffic crash rates.

As for indirect effects of the study variables on work traffic crashes, the need for recovery (work-related fatigue) has shown to exert full mediations between three variables, 1) general physical health, 2) psychological distress, 3) job strain and self-reported WTCs. In summary, the results of the structural model statistically endorse the assumption raised in hypothesis $3(\mathrm{H} 3)$, ie, that fatigue exerts the role of statistical

Table 4 Variables Included in the Model, Estimates and Significance Levels of the SEM Paths for Explaining Work-Traffic Crashes in a Period of 2 Years

\begin{tabular}{|l|l|l|c|c|c|c|}
\hline \multicolumn{2}{|l|}{ Variable } & SPC $^{\mathbf{a}}$ & S.E. $^{\mathbf{b}}$ & C.R. $^{\mathbf{c}}$ & $\boldsymbol{P}^{\mathbf{d}}$ \\
\hline Age & $\rightarrow$ & Work-Related Fatigue (NFR) & -0.065 & 0.016 & -1.883 & 0.060 \\
Daily Shift Intensity (Hours) & $\rightarrow$ & Work-Related Fatigue (NFR) & 0.087 & 0.071 & 2.534 & $*$ \\
General Health Index & $\rightarrow$ & Work-Related Fatigue (NFR) & -0.265 & 0.078 & -6.883 & $* * *$ \\
Psychological Distress & $\rightarrow$ & Work-Related Fatigue (NFR) & 0.350 & 0.031 & 8.793 & $* * *$ \\
Job Strain & $\rightarrow$ & Work-Related Fatigue (NFR) & 0.205 & 0.437 & 5.501 & $* * *$ \\
Age & $\rightarrow$ & Work Traffic Crashes & -0.134 & 0.006 & -3.038 & $* *$ \\
Daily Shift Intensity (Hours) & $\rightarrow$ & Work Traffic Crashes & -0.025 & 0.026 & -0.549 & 0.583 \\
Job Strain & $\rightarrow$ & Work Traffic Crashes & 0.011 & 0.191 & 0.188 & 0.851 \\
Work-Related Fatigue (NFR) & $\rightarrow$ & Work Traffic Crashes & 0.271 & 0.025 & 2.988 & $* *$ \\
\hline
\end{tabular}

Notes: ${ }^{d} p$-value: *significant at the level $p<0.05 ; * *$ significant at the level $p<0.01$; ***significant at the level $p<0.00$.

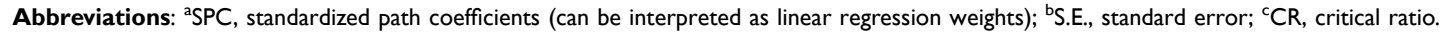


mediator in the relationship between job strain and the occupational crashes suffered by long-haul truck drivers.

\section{Discussion}

Once tested the basic assumptions of the study in light of its core aim (ie, to assess the role of NFR as a potential mediator between driver's psychosocial work factors and WTCs), the results of this research support the idea that work-related fatigue fully mediates this chain. Through the performed structural analyses, it is feasible to affirm that occupational traffic crashes of long-haul truck drivers can be statistically explained if job stress (in this case assessed through the JDC model) and health factors are considered. Concretely, the main finding of this research is that, coherently with the general study hypothesis (H3), there is a significant chain involving work-related factors and fatigue in the causation of the occupational accidents (traffic crashes) suffered by long-haul truck drivers, where fatigue exerts a mediating role between health indicators and job stress (independent variables) and work traffic crashes.

Another relevant aspect of the model is that, according to hypothesis $1(\mathrm{H} 1)$, job strain has a positive effect on fatigue although not necessarily on work traffic crashes. The first aspect is coherent with the findings of van der Hulst et al (2006) ${ }^{43}$ in a study dealing with an extensive sample of workers from different occupations; workers with higher scores in job strain (allocated in the job strain quadrant of the JDC model) report a significantly higher need for recovery (work-related fatigue) indexes than those classified in any other quadrant of the model. Also, in a repeated measure-design, de Lange et al (2009) ${ }^{44}$ have correlated fatigue with job demands (positively) and job control (negatively), coherently with what is observed in this study based on the JDC model, in which higher demands combined with low control imply job stress.

As for the second aspect (the absence of a directly significant path between job strain and crashes), a similar study performed with Bus Rapid Transit (BRT) professional drivers allowed for the establishment that the mechanism by which job strain is linked to risky driving behaviors is the need for recovery that fully and positively mediates this association. ${ }^{17}$ In the case of this study, the dependent variable was not risky driving behavior increasing crash likelihood - but the number of crashes suffered. Nevertheless, the positive directionality and magnitude of the correlation between risky driving behaviors (both errors and violations) and traffic crashes tend to be consistently reliable across several studies carried out with professional drivers. ${ }^{6}$ Also, the association between job strain and various measures of driving fatigue - even others outside Sluiter's NFR approach, is consistently significant and positive in the literature. ${ }^{45,46}$

The effect of job stress on work-related fatigue, however, is not consistent across all theoretical approaches. In previous studies, stress-related models such as the EffortReward Imbalance ${ }^{47}$ have been tested in relation to the need for recovery and risky behaviors of professional drivers, finding that, unlike Karasek's Job DemandControl model, ${ }^{21}$ work-related stress directly explains the risky behaviors of drivers. ${ }^{17}$ This difference could be explained if it is considered that the stress indicator of the ERI model is built up as the disparity between the efforts put into the work-related tasks and the intrinsic/ extrinsic rewards perceived by workers as a result of their job. ${ }^{14}$ Coherently, Sembajwe et al $(2012)^{48}$ have determined that the actors composing the JDC and ERI models address different aspects of workplace stress, and the significance of their scales can be variably significant in regression-based analyses.

A key difference between both approaches is that the ERI model includes more distant macroeconomic labor market aspects, such as job security, while the JDC model focuses on the characteristics of the job. However, for our study, it seemed more parsimonious to follow the JDC perspective for operationalizing driving-related factors, since the factor structure followed by the JDC model addresses (eg) psychological demands, skill discretion and decision authority, that 1) are easily translatable to the onroad tasks performed by professional drivers and 2) have shown significant relationships with both objective and subjective work-related fatigue measures in previous studies specifically performed with truck drivers. ${ }^{34,49}$

Moreover, and in regard to hypothesis 2 (H2), according to which fatigue is positively related to work-traffic crash rates, there is an extensive background supporting the idea that work-related fatigue influences both riskydriving behaviors and traffic crashes of commercial drivers. ${ }^{13,16,17,50}$ In the specific case of commercial driving, the work of May and Baldwin (2009) ${ }^{51}$ offers interesting insights on the problematic role of task-related fatigue within the driving performance, through a set of impairments that include substantial reductions in visual scanning patterns and eye movements. Furthermore, Camden et al (2017) ${ }^{52}$ have described how work features of professional drivers' sustained driving in demanding conditions may lead to cognitive overload (enhanced by 


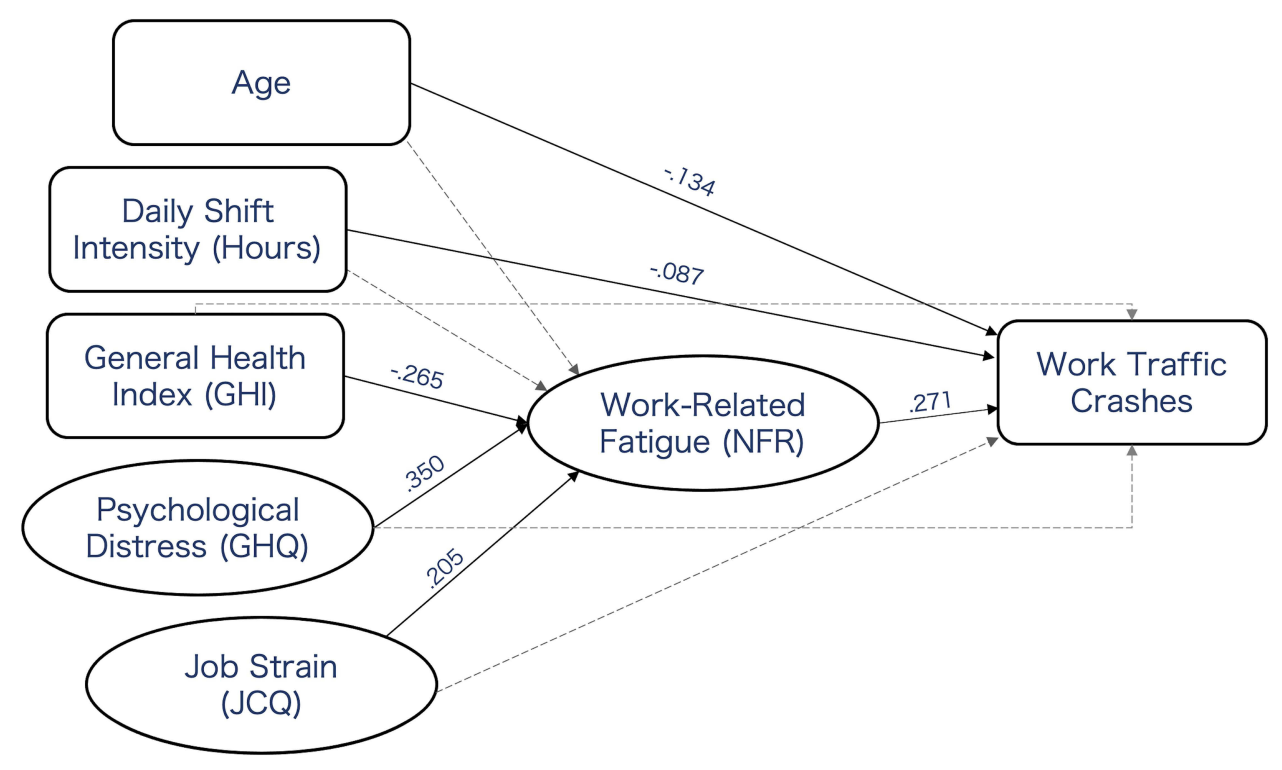

Figure 2 Standardized parameter estimates. Solid lines represent significant paths.

Notes: All estimates listed in solid lines are significant (as shown in Table 3); ellipses represent inferred (latent) variables; squares represent observed ones.

many typical secondary tasks, eg, reading traffic signs and anticipating the behaviors of other drivers), simultaneously related to an increased likelihood to suffer a crash. ${ }^{53}$

Linked to the aforementioned, another issue that must be (at least briefly) discussed is the negative directionality of the path between long-haul drivers' age and their selfreported work-traffic crash rate, an aspect that has been raised by previous studies dealing with professional drivers, where the correlation between age and crashes remains negative and statistically significant. In this regard, two issues are worth describing; firstly, that professional drivers' age represents an overall good predictor of their safety-related critical events; ${ }^{54}$ and secondly, that other studies predicting risky driving behavior have also consistently found a negative association between age/ driving experience (that tend to be collinear factors) and risky driving behaviors reported by professional drivers. ${ }^{17}$

Notwithstanding, it must be also noted that, overall, literature endorses the idea that professional drivers' age plays a "relative" protective role on their traffic safety outcomes, as - linked to the typical psychophysiological impairments of aging - its positive effect tends to decrease by the age of 5560 years. ${ }^{55,56}$ In this regard, the significance of the bivariate correlation (Table 3) and the Path (Table 4 and Figure 2) between participants' age and their work traffic crash rates is consistent to the demographic features of this sample of truck drivers, whose mean age was 47 years.
Finally, an added (and relevant) aspect of this study that is worth examining is the role of both health-related measures as confounders in the relationship between need for recovery and crashes among long-haul truck drivers: whereas the General Health Index (GHI) has a negative association with fatigue scores (ie, drivers with a better physical health status develop lower NFR indexes), psychological distress (GHQ) enhances the appearance of a higher need for recovery levels. This set of significant associations highlights the importance of addressing the driver's both physical and mental health settings as a manner of strengthening his/her occupational safety. ${ }^{57}$ In previous researches, self-rated health of workers, apart from being defined as a solid predictor of fatigue, has been related to different negative outcomes, such as early retirement, ${ }^{58,59}$ poorer fatigue-recovery patterns, short-term absenteeism ${ }^{60}$ and several crash-related outcomes (ie, accidents, injuries/disability and deaths) latently threatening the safety and welfare of commercial drivers. ${ }^{6,50}$

\section{Limitations of the Study}

Although this study analyzed a considerably large dataset, representative of the population of long-haul truck drivers in Spain and the validity and reliability of the applied questionnaires had been endorsed by both previously an extensive empirical background and adequate psychometric indexes, some potential bias could have affected the study process and/or outcomes. 
Firstly, this study was carried out based on self-report data. In brief, and although key issues such as the anonymity of the provided data and the solely scientific value of the information provided were guaranteed, self-report measures still imply potential biases, including socially desirable or acquiescent responses. ${ }^{61}$

Secondly, objective driving safety outcomes could differ from the self-reported ones. ${ }^{62}$ In this regard, we suggest other researchers consider the use of 1) scales intended to measure and control potential biasing sources that may influence the results of predictive studies, ${ }^{63}$ and 2) measures dealing with specific risky driving behaviors that also could be understood as crash predictors. ${ }^{64,65}$

Thirdly, and given both its theoretical framework and the limitation of the questionnaire length (typical from self-report-based studies), this study was focused on psychosocial and health-related conditions and potential predictors of work traffic crashes. Notwithstanding, this does not imply that other factors (eg, infrastructural, weather and vehicle-related issues) do not constitute reliable occupational crash predictors; on the contrary, their relevance has been endorsed by company and crash-record-based studies. $^{26,54}$ Therefore, it must be highlighted that other factors could act as complementary predictors influencing work-related fatigue and crashes suffered by long-haul drivers, and this must be considered for interpreting the outcomes of this study.

Finally, and consistently with the overrepresentation of male drivers in the transportation industry (in this study, we had $96.7 \%$ male participants), sex-based comparisons could not be performed.

\section{Conclusion}

This study aimed to contribute to this field by developing a theoretically based empirical model that can simultaneously assess the impact of job stress, health issues and fatigue on the occupational traffic crashes suffered by long-haul truck drivers. In summary, the results of this study have shown how:

1) Job strain and health-related variables are significantly associated with the work-related fatigue levels of long-haul truck drivers.

2) Work-related fatigue, enhanced by long driving shifts, health issues and job strain, is positively related to the work-traffic crash they suffer.

3) Fatigue exerts the role of statistical full-mediator on the relationship between job strain and the occupational crashes suffered by them.

\section{Practical Implications and Applications}

The results of this study suggest that NFR (work-related fatigue) constitutes a critical issue for long-haul drivers' both occupational and road safety.

Secondly, and apart from influencing their occurrence, fatigue mediates the relationships among key factors such as job strain and physical/mental health indicators and these crashes. Hence, and apart from stress-related interventions, it is worth highlighting the value of fatigue-management interventions at the workplace for long-haul drivers as potentially effective strategies for reducing work-related crashes.

\section{Acknowledgments}

The authors would like to thank the participants, research assistants and institutional stakeholders involved in the data collection. We should especially thank the National Federation of Transport Associations of Spain (FENADISMER) and the Spanish Foundation for Road Safety (FESVIAL) for their permanent collaboration during the data collection phase. Finally, we want to acknowledge Mireia Faus (PhD student) for technically advising the study and Arash Javadinejad for professional editing and proofreading the final version of the manuscript.

\section{Disclosure}

The authors report no conflicts of interest in this work.

\section{References}

1. Bliese PD, Edwards JR, Sonnentag S. Stress and well-being at work: a century of empirical trends reflecting theoretical and societal influences. J Appl Psychol. 2017;102(3):389-402. doi:10.1037/ap10000109

2. Li J, Riedel N, Barrech A, et al. Long-term effectiveness of a stress management intervention at work: a 9-year follow-up study based on a randomized wait-list controlled trial in male managers. Biomed Res Int. 2017:2853813. doi:10.1155/2017/2853813

3. Leka S, Jain A, Iavicoli S, Di Tecco C. An evaluation of the policy context on psychosocial risks and mental health in the workplace in the European Union: achievements, challenges, and the future. Biomed Res Int. 2015;213089. doi:10.1155/2015/213089

4. Havermans BM, Brouwers EPM, Hoek RJA, Anema JR, Van der Beek AJ, Boot CRL. Work stress prevention needs of employees and supervisors. BMC Public Health. 2018;18(1):642. doi:10.1186/s12889-018-5535-1

5. Van der Klink JJ, Blonk RW, Schene AH, Van Dijk FJ. The benefits of interventions for work-related stress. Am J Public Health. 2001;91 (2):270-276. doi:10.2105/ajph.91.2.270

6. Useche SA, Cendales B, Montoro L, Esteban C. Work stress and health problems of professional drivers: a hazardous formula for their safety outcomes. Peer J. 2018;6:e6249. doi:10.7717/peerj.6249

7. Hege A, Lemke MK, Apostolopoulos Y, Sönmez S. Occupational health disparities among U.S. long-haul truck drivers: the influence of work organization and sleep on cardiovascular and metabolic disease risk. PLoS One. 2018;13(11):e0207322. doi:10.1371/journal. pone. 0207322 
8. Lemke M, Apostolopoulos Y. Health and wellness programs for commercial motor-vehicle drivers: organizational assessment and new research directions. Workplace Health Saf. 2015;63(2):71-80. doi: $10.1177 / 2165079915569740$

9. Gastaldi M, Rossi R, Gecchele G. Effects of driver task-related fatigue on driving performance. Procedia Soc Behav Sci. 2014;111:955-964. doi:10.1016/j.sbspro.2014.01.130

10. Hege A, Lemke MK, Apostolopoulos SS, Sönmez S. The impact of work organization, job stress, and sleep on the health behaviors and outcomes of U.S. long-haul truck drivers. Health Educ Behav. 2019;46(4):626-636. doi:10.1177/1090198119826232

11. Gómez V, Cendales B, Useche S, Bocarejo JP. Relationships of working conditions, health problems and vehicle accidents in bus rapid transit (BRT) drivers. Am J Ind Med. 2018;1-8. doi:10.1002/ ajim. 22821

12. Boada-Grau J, Sánchez-García JC, Prizmic-Kuzmica AJ, Vigil-Colet A. Health and safety at work in the transport industry (TRANS-18): factorial structure, reliability and validity. Span J Psychol. 2012;15 (1):357-366. doi:10.5209/revsjop.2012.v15.n1.37342

13. Chen GX, Sieber WK, Lincoln JE, Birdsey J, Hitchcock EM. NIOSH national survey of long-haul truck drivers. Inj Saf Accid Anal Prev. 2015;85:66-72. doi:10.1016/j.aap.2015.09.001

14. Tse JL, Flin R, Mearns K. Facets of job effort in bus driver health: deconstructing "effort" in the effort-reward imbalance model. J Occup Health Psychol. 2007;12(1):48-62. doi:10.1037/10768998.12.1.48

15. European Commission. Fatigue 2018. Web resource; 2018. Available from: https:/ec.europa.eu/transport/road_safety/sites/roadsafety/files/ pdf/ersosynthesis2018-fatigue.pdf. Accessed July 27, 2021.

16. Garbarino S, Guglielmi O, Sannita WG, Magnavita N, Lanteri P. Sleep and mental health in truck drivers: descriptive review of the current evidence and proposal of strategies for primary prevention. Int J Environ Res Public Health. 2018;15(9):1852. doi:10.3390/ ijerph15091852

17. Useche SA, Gómez V, Cendales B. Stress-related psychosocial factors at work, fatigue, and risky driving behavior in bus rapid transport (BRT) drivers. Accid Anal Prev. 2017;104:106-114. doi:10.1016/j. aap.2017.04.023

18. Useche SA, Montoro L, Cendales B, Gómez V. Job strain in public transport drivers: data to assess the relationship between demand-control model indicators, traffic accidents and sanctions. Data Brief. 2018;19C:293-298. doi:10.1016/j.dib.2018.05.036

19. Taylor A, Dorn L. Stress, fatigue, health, and risk of road traffic accidents among professional drivers: the contribution of physical inactivity. Public Health. 2006;27(1):371-391. doi:10.1146/annurev. publhealth.27.021405.102117

20. Raggatt PT, Morrissey SA. A field study of stress and fatigue in long-distance bus drivers. Beh Med. 1997;23(3):122-129. doi:10.1080/08964289709596368

21. Karasek R. Demand/Control Model: A Social, Emotional, and Physiological Approach to Stress Risk and Active Behavior Development. 4th ed. Princeton, Geneva: ILO Encyclopedia of Occupational Health and Safety; 1998.

22. Turner N, Stride CB, Carter AJ, McCaughey D, Carroll AE. Job demands-control-support model and employee safety performance. Accid Anal Prev. 2012;45:811-817. doi:10.1016/j.aap.2011.07.005

23. Spector PE, Jex SM. Development of four self-report measures of job stressors and strain: interpersonal conflict at work scale, organizational constraints scale, quantitative workload inventory, and physical symptoms inventory. J Occup Health Psychol. 1998;3(4):356-367. doi:10.1037//1076-8998.3.4.356

24. Martí-Belda A, Pastor JC, Montoro L, Bosó P, Roca J. Persistent traffic offenders: alcohol consumption and personality as predictors of driving disqualification. Eur J Health Psychol. 2019;11:81-92. doi:10.5093/ejpalc2019a3
25. Desmond P, Matthews G. Individual differences in stress and fatigue in two field studies of driving. Transport Res F Traf. 2009;12 (4):265-276. doi:10.1016/j.trf.2008.12.006

26. Useche SA, Gómez V, Cendales B, Alonso F. Working conditions, job strain and traffic safety among three groups of public transport drivers. Saf Health Work. 2018;9(4):454-461. doi:10.1016/j. shaw.2018.01.003

27. Useche S, Cendales B, Gómez V. Work stress, fatigue and risk behaviors at the wheel: data to assess the association between psychosocial work factors and risky driving on bus rapid transit drivers. Data Brief. 2017;15:335-339. doi:10.1016/j.dib.2017.09.032

28. Van Veldhoven M, Broersen S. Measurement quality and validity of the "need for recovery scale". Occup Environ Med. 2003;60(SupplI): i3-i9. doi:10.1136/oem.60.suppl_1.i3

29. De Croon EM, Sluiter JK, Blonk RW, Broersen JP, Frings-Dresen MH. Stressful work, psychological job strain, and turnover: a 2-year prospective cohort study of truck drivers. J Appl Psychol. 2004;89 (3):442-454. doi:10.1037/0021-9010.89.3.442

30. De Vries J, Michielsen HJ, Van Heck GL. Assessment of fatigue among working people: a comparison of six questionnaires. Occup Environ Med. 2003;60(SupplI):i10-i15. doi:10.1136/oem.60.suppl_1.i10

31. Kee S, Mohd S, Driving Fatigue GY. Performance among occupational drivers in simulated prolonged driving. Glob J Health Sci. 2010;2(1):167-177. doi:10.5539/gjhs.v2n1p167

32. Gómez V. Assessment of psychosocial stressor at work: psychometric properties of the Spanish version of the JCQ (job content questionnaire) in Colombian workers. Rev Lat Psicol. 2011;43(2):125-138.

33. Sluiter JK, De Croon EM, Meijman TF, Frings-Dresen MH. Need for recovery from work related fatigue and its role in the development and prediction of subjective health complaints. Occup Environ Med. 2003;60(SupplI):i62-i70. doi:10.1136/oem.60.suppl_1.i62

34. De Croon EM, Sluiter JK, Frings-Dresen MHW. Psychometric properties of the need for recovery after work scale: test-retest reliability and sensitivity to detect change. Occup Environ Med. 2006;63 (3):202-206. doi:10.1136/oem.2004.018275

35. Kristensen TS, Hannerz H, Høgh A, Borg V. The Copenhagen psychosocial questionnaire - a tool for the assessment and improvement of the psychosocial work environment. Scand J Work Environ Health. 2005;31(6):438-449. doi:10.5271/sjweh.948

36. Goldberg D. General Health Questionnaire (GHQ-12). Windsor: NFER-Nelson; 1992.

37. Useche SA, Cendales B, Alonso F, Montoro L. Multidimensional prediction of work traffic crashes among Spanish professional drivers in cargo and passenger transportation. Int $J$ Occup Saf Ergo. 2020;1-8. doi:10.1080/10803548.2020.1732102

38. Sluiter JK, van der Beek AJ, Frings-Dresen MH. Workload of Coach Drivers. [Werkbelasting Touringcarchauffeurs]. Amsterdam: Academic Medical Centre, Coronel Institute for Occupational and Environmental Health, University of Amsterdam; 1997:1-71. Rep. No. 97-03.

39. Morrow PC, Crum MR. Antecedents of fatigue, close calls, and crashes among commercial motor-vehicle drivers. J Safety Res. 2004;35(1):59-69. doi:10.1016/j.jsr.2003.07.004

40. Gunzler $\mathrm{D}$, Chen $\mathrm{T}$, Wu $\mathrm{P}$, Zhang $\mathrm{H}$. Introduction to mediation analysis with structural equation modeling. Shanghai Arch Psychiatry. 2013;25(6):390-394. doi:10.3969/j.issn.10020829.2013.06.009

41. Merchant WR, Li J, Karpinski AC, Rumrill, Jr. PD Jr. A conceptual overview of structural equation modeling (SEM) in rehabilitation research. Work. 2013;45(3):407-415. doi:10.3233/WOR-131633

42. Marsh HW, Hau KT, Wen Z. In search of golden rules: comment on hypothesis-testing approaches to setting cutoff values for fit indexes and dangers in over generalizing Hu and Bentler's (1999) findings. Struct Equ Modeling. 2004;11:320-341. doi:10.1207/ s15328007sem1103_2 
43. Van der Hulst M, van Veldhoven M, Beckers D. Overtime and need for recovery in relation to job demands and job control. J Occup Health. 2006;48(1):11-19. doi:10.1539/joh.48.11

44. De Lange AH, Kompier Michielaj, Taris TW, et al. A hard day's night: a longitudinal study on the relationships among job demands and job control, sleep quality and fatigue. J Sleep Res. 2009;18 (3):374-383. doi:10.1111/j.1365-2869.2009.00735.x

45. Arnold PK, Hartley LR. Policies and practices of transport companies that promote or hinder the management of driver fatigue. Transport Res F Traf. 2001;4(1):1-17. doi:10.1016/S1369-8478(01)00010-9

46. Langan-Fox J, Cooper CL. Handbook of Stress in the Occupations. Northampton: Edward Elgar Publishing, Inc; 2001.

47. Siegrist J. Effort-Reward Imbalance at work and Health in Historical and Current Perspectives on Stress and Health. Ganster D, Perrewe P, editors. Vol. 2. Amsterdam: Elsevier Science Ltd.; 2002:261-291.

48. Sembajwe G, Wahrendorf M, Siegrist J, et al. Effects of job strain on fatigue: cross-sectional and prospective views of the job content questionnaire and effort-reward imbalance in the GAZEL cohort. Occup Environ Med. 2012;69(6):377-384. doi:10.1136/oem.2010.063503

49. Ulhôa MA, Marqueze EC, Kantermann T, Skene D, Moreno C. When does stress end? Evidence of a prolonged stress reaction in shiftworking truck drivers. Chronobiol Int. 2011;28(9):810-818. doi:10.3109/ 07420528.2011 .613136

50. National Academies of Sciences, Engineering and Medicine. Commercial Motor Vehicle Driver Fatigue, Long-Term Health, and Highway Safety: Research Needs. Washington, DC: The National Academies Press; 2016. 17226/21921.

51. May JF, Baldwin CL. Driver fatigue: the importance of identifying causal factors of fatigue when considering detection and countermeasure technologies. Transport Res F Traf. 2009;12(3):218-224. doi:10.1016/j.trf.2008.11.005

52. Camden MC, Hickman JS, Soccolich SA, Hanowski RJ. Identification and Recommendations for Correction of Equipment Factors Causing Fatigue in Snowplow Operations. Blacksburg: Virginia Tech Transportation Institute; 2017. Technical Report No. CR 15-02.

53. Lyu N, Xie L, Wu C, Fu Q, Deng C. Driver's cognitive workload and driving performance under traffic sign information exposure in complex environments: a Case Study of the highways in China. Int J Environ Res Public Health. 2017;14(2):203. doi:10.3390/ ijerph14020203

54. Mehdizadeh A, Alamdar Yazdi MA, Cai M, et al. Predicting unsafe driving risk among commercial truck drivers using machine learning: lessons learned from the surveillance of 20 million driving miles. Accid Anal Prev. 2021;159:106285. doi:10.1016/j.aap.2021.106285

55. Duke J, Guest M, Boggess M. Age-related safety in professional heavy vehicle drivers: a literature review. Accid Anal Prev. 2010;42 (2):364-371. doi:10.1016/j.aap.2009.09.026

56. Mayhew DR, Simpson HM, Beirness DJ. Heavy Trucks and Road Crashes. Ottawa: Traffic Injury Research Foundation;2004. Available from: https://tirf.ca/wp-content/uploads/2017/02/Heavy_Trucks Report.pdf. Accessed July 27, 2021.

Psychology Research and Behavior Management

Publish your work in this journal

Psychology Research and Behavior Management is an international, peer-reviewed, open access journal focusing on the science of psychology and its application in behavior management to develop improved outcomes in the clinical, educational, sports and business arenas. Specific topics covered in the journal include: Neuroscience, memory and decision making; Behavior modification and management; Clinica

Submit your manuscript here: https://www.dovepress.com/psychology-research-and-behavior-management-journa
57. Stavrinos D, Heaton K, Welburn SC, McManus B, Griffin R, Fine PR. Commercial truck driver health and safety: exploring distracted driving performance and self-reported driving skill. Workplace Health Saf. 2016;64(8):369-376. doi:10.1177/ 2165079915620202

58. Mein G. Predictors of early retirement in British civil servants. Age Ageing. 2000;29(6):529-536. doi:10.1093/ageing/29.6.529

59. Henekens K, Tazelaar F. Early retirement of civil servants in the Netherlands. J Appl Soc Psychol. 1994;24(21):1927-1943. doi:10.1111/j.1559-1816.1994.tb00568.x

60. Cunradi CB, Greiner BA, Ragland DR, Fisher J. Alcohol, stress-related factors, and short-term absenteeism among urban transit operators. J Urban Health. 2005;82(1):43-57. doi:10.1093/jurban/ jti007

61. Brenner PS, DeLamater J. Lies, damned lies, and survey self-reports? Identity as a cause of measurement bias. Soc Psychol Quart. 2016;79 (4):333-354. doi:10.1177/0190272516628298

62. Chai J, Qu W, Sun X, Zhang K, Ge Y. Negativity bias in dangerous drivers. PLoS One. 2016;11(1):e0147083. doi:10.1371/journal. pone. 0147083

63. Rosenman R, Tennekoon V, Hill LG. Measuring bias in self-reported data. Int J Behav Health Res. 2011;2(4):320-332. doi:10.1504/ IJBHR.2011.043414

64. Mehdizadeh M, Shariat-Mohaymany A, Nordfjaern T. Driver behaviour and crash involvement among professional taxi and truck drivers: light passenger cars versus heavy goods vehicles. Transport Res F Traf. 2019;62:86-98. doi:10.1016/j.trf.2018.12.010

65. Maslać M, Antić B, Pešić D, Milutinović N. Behaviours of professional drivers: validation of the DBQ for drivers who transport dangerous goods in Serbia. Transport Res F Traf. 2017;50:80-88. doi:10.1016/j.trf.2017.08.001

66. Xia Y, Yang Y. RMSEA, CFI, and TLI in structural equation modeling with ordered categorical data: the story they tell depends on the estimation methods. Behav Res Methods. 2019;51(1):409-428. doi:10.3758/s13428-018-1055-2

67. Shi D, Lee T, Maydeu-Olivares A. Understanding the model size effect on SEM fit indices. Educ Psychol Meas. 2019;79(2):310-334. doi:10.1177/0013164418783530

68. Bentler PM. Comparative fit indexes in structural models. Psychol Bull. 1990;107(2):238-246. doi:10.1037/0033-2909.107.2.238

69. Ullman JB. Structural equation modeling. In: Tabachnick BG, Fidell LS, editors. Using Multivariate Statistics. 5th ed. Boston, MA: Pearson Education Inc; 1996:676-780.

70. Bollen KA. A new incremental fit index for general structural equation models. Sociol Methods Res. 1989;17(3):303-316. doi:10.1177/ 0049124189017003004 applications; Business and sports performance management; Social and developmental studies; Animal studies. The manuscript management system is completely online and includes a very quick and fair peer-review system, which is all easy to use. Visit http://www. dovepress.com/testimonials.php to read real quotes from published authors. 